\title{
LXIII PBhillo]logiga
}

CZU:821.135.1(478).09

https://doi.org/10.52505/1857-4300.2021.1(313).05

ORCID: 0000-0002-0042-0289

\section{SVETLANA KOROLEVSKI}

Institutul de Filologie Română

„Bogdan Petriceicu-Hasdeu”

(Chişinău)

\section{HASDEU ŞI OPERA SA ÎN CERCETĂRILE DE LA CHIŞINĂU}

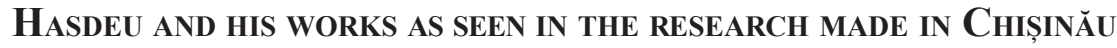

\begin{abstract}
The theme of Hasdeu and his works as seen in the research made in Chișinău involves two guidelines that complement each other: the editing of the work itself and the exegesis dedicated to Hasdeu's heritage. Several Bessarabian researchers and publicists have commented on Hasdeu's personality, including in the interwar period. A special place among the contributions regarding Hasdeu's legacy is occupied by the studies signed by Nicolae Romanenco, who, since the 1950s, has boosted the research and editing of the work of the great classic in Chișinău. The biographical course of B.P.-Hasdeu, the vast literary and scientific work were the object of thorough and documented study of researchers such as Gh. Bogaci, I. Vasilenco, H. Corbu, P. Zavulan, V. Cirimpei, V. Ciocanu, S. Berejan, P. Balmuș, V. Malaneți, M. Cimpoi, Gh. Bobână and others, whose approaches prove the uniqueness of Hasdeian spirit and its deep commitment in contemporaneity.
\end{abstract}

Keywords: legacy, hasdeology, Hasdeu spirit, research, publishing, Bessarabian area, contemporaneity.

Rezumat. Tema Hasdeu şi opera sa în cercetările de la Chişinău presupune două linii directoare care se completează reciproc: editarea operei propriu-zise şi exegezele consacrate moştenirii hasdeiene. Asupra personalităţii lui Hasdeu s-au pronunţat mai mulţi cercetători şi publicişti basarabeni, inclusiv în perioada interbelică. Un loc aparte între contribuţiile privind moştenirea Hasdeu îl ocupă studiile semnate de Nicolae Romanenco, care, încă din anii '50 ai secolului trecut, a impulsionat activitatea de cercetare şi editare a operei marelui clasic la Chişinău. Parcursul biografic al lui B. P.- Hasdeu, vasta operă literară şi ştiinţifică au constituit obiectul de studiu atent şi documentat al cercetătorilor Gh. Bogaci, I. Vasilenco, H. Corbu, P. Zavulan, V. Cirimpei, V. Ciocanu, S. Berejan, P. Balmuş, V. Malaneţchi, M. Cimpoi, Gh. Bobână Ş.a., ale căror abordări fac dovada unicităţii spiritului hasdeian şi a profundei sale angajări în contemporaneitate.

Cuvinte-cheie: moştenire, hasdeologie, spirit hasdeian, cercetare, editare, spaţiu basarabean, contemporaneitate. 
Vastitatea preocupărilor hasdeiene, deschiderile enciclopedice care marchează demersul său intelectual, apropiindu-l de gândirea lumii occidentale, efortul titanic neobosit, egalabil în epocă poate doar cu cel al lui Eminescu, au uimit, au incitat, de-a lungul timpului, generând, fortificând, permanentizând legăturile spirituale între generaţiile care i-au urmat.

Tema anunţată - Hasdeu şi opera sa în cercetările de la Chişinău - cuprinde un dublu aspect, două linii directoare care se completează reciproc: editarea aici, în acest spaţiu, a operei propriu-zise şi abordarea ştiinţifică, investigaţiile consacrate moştenirii hasdeiene.

Asupra personalităţii lui Hasdeu s-au pronunţat mai mulţi exegeţi basarabeni, care tratează pe larg, uneori cu lux de amănunte, viaţa (în special perioada de început) şi activitatea scriitorului, dar şi impresionanta sa operă literară şi ştiinţifică.

Chişinăul interbelic reţine câteva titluri, două dintre care, B. P. Hasdeu şi Rusia (1925) şi B. P. Hasdeu şi M. Eminescu (1927), urmate de un al treilea, De la Hasdeu cetire. Mănunchiu de cugetări... (1932), aparţin lui Liviu Marian, scriitor bucovinean, fiul folcloristului-preot Simion Florea Marian, profesor şi director al Liceului „B. P. Hasdeu” din urbe. O schiţă biografică şi bibliografică, Bogdan Petriceicu Hasdeu, va scoate Liviu Marian în 1928 şi la Bucureşti. O altă lucrare, Bogdan Petriceicu Hasdeu (1939), este semnată de Pan Halippa. Toate, însă, mici ca volum, nedepăşind per titlu 30 de pagini. Din aceeaşi perioadă datează şi preocupările de hasdeologie ale publiciştilor Ion Pelivan, T. G. Bulat, Pan Halippa, Zamfir Arbore ş.a., ale căror intervenţii se regăsesc în periodicele basarabene (Viaţa Basarabiei ş.a.), alături de fragmente din Ioan-Vodă cel Cumplit, cugetări şi unele poezii ale scriitorului. Să amintim şi articolul B. P. Hasdeu (1836-1907), de Gheorghe Andronachi, publicat în 1933, în volumul Albumul Basarabiei în jurul marelui eveniment al Unirii, reeditat în 2000 la Bucureşti.

Tonul însă în cercetările chişinăuiene privind viaţa şi opera marelui clasic avea să-1 dea, în dificilii ani postbelici (1957!), „,cel care, sunt convins, - zice Vladimir Beşleagă într-un cunoscut eseu - şi 1-a luat din tinereţe drept model pe marele Hasdeu" (Beşleagă, 2005, p. 118). Monografia lui Nicolae Romanenco Bogdan Petriceicu Hasdeu. Viaţa şi opera (1836-1907) apare la Editura de stat a Moldovei, într-un tiraj (de invidiat astăzi) de 5000 de exemplare, numărând 195 de pagini, care cuprind: o succintă prefaţă, Scriitor, publicist, om de ştiinţă capitolele: Fragmente biografice (Anii tinereții; Perioada ieşeană; Avântare în luptă şi creaţie); Creaţia artistică (Pentru o literatură norodnică şi realistă; Lirică şi satiră socială; Răzvan şi Vidra; Ioan-Vodă cel Cumplit); Activitatea publicistică (Continuator al tradiţiilor paşoptiste; Apărătorul intereselor ţărănimii; Patriot şi umanist); Opera ştiinţifică (Istoria critică ; Filologie comparativă; Cuvinte din bătrâni; Dicţionarul limbii istorice şi poporane) şi la Addenda: Lucrările lui B. P. Hasdeu tipărite în ediţii aparte, 1864-1897 


\section{LXIII

(23 de surse); Ziare şi reviste redactate de B. P. Hasdeu (10 titluri); Literatura folosită (Scrierile lui B. P. Hasdeu: a) Lucrări publicate în timpul vieții; b) Editii postume comentate).

„Dvs. aveţi toate scrupulele unui riguros om de ştiinţă. Sub raportul stilului, al limbii curgătoare şi uşor de urmat - al informaţ̧iei aproape exhaustive, al poziţiei critice şi al sintezei, lucrarea prezintă la noi merite de pionierat", desprindem dintr-o scrisoare către N. Romanenco, datată Bucureşti, 27 august 1958 (In memoriam N. N. Romanenco..., 2006, p. 171).

O apreciere care încuraja şi determina autorul să continue pe acelaşi făgaş. Doi ani mai târziu (1959), apare versiunea în limba rusă a monografiei, într-un tiraj de 3000 de exemplare, la editura Cartea Moldovei. Prima ediţie de Opere alese apare în 1956, sub îngrijirea Verei Panfil şi a lui Nicolae Romanenco, incluzând, selectiv: Poezie; Proză; Dramaturgie; Critică şi publicistică; un an mai târziu, Răzvan şi Vidra, în ediţie aparte. Aceste cărţi erau parte a muncii de recuperare a valorilor spirituale ale trecutului, în care se încadrează scriitori şi filologi animaţi de dorinţa salvgardării culturii naţionale.

Bătălia pentru afirmarea/ valorificarea moştenirii clasice a fost, se ştie, dură. Procesul de renaştere culturală declanşat ca urmare a sesiunii Academiei din decembrie 1951, cu rezoluţia care stipula: a se revedea problema limbii literare şi cea a moştenirii clasice a fost periclitat. $\mathrm{O}$ abordare sociologică vulgarizantă privind cercetarea fenomenului literar apare, la începutul anului 1959, în paginile oficiosului „Kommunist Moldavii”. Presiunea exercitată de organele puterii anihila, practic, ceea ce se reuşise în ultimii ani în munca de revalorificare. Lui N. Romanenco, în parte, i se incriminau, ,ideile burgheze" pe care le-ar fi strecurat în monografie. A urmat şi o explicaţie din partea editurii. Nolens-volens angajaţii Editurii de stat a Moldovei (V. Cherdivarenco, P. Didâc, A. Roşca, A. Lipcan, L. Culic) vor semna misiva (evident, în limba rusă!) către redacţia ziarului, în care concluzionau: „Editura de stat Cartea Moldovei a editat în 1959 cărţile Iarba fiarelor de G. Meniuc şi B. P. Hasdeu de N. Romanenco. Aceste cărţi conţin greşeli ideologice de principiu. Din neatenţia editurii, în lista de literatură utilizată de N. Romanenco în monografia B. P. Hasdeu sunt incluse un şir de lucrări ale autorilor de orientare reacţionară străini... În prezent colectivul editurii ia măsuri radicale de a nu mai admite în activitatea sa greşeli ideologice" (In memoriam N. N. Romanenco..., 2006, p. 237; Kulikovski, 2007, p. 27).

Aceste circumstanţe au determinat derularea unei ample discuţii despre literatura moldovenească în paginile revistei moscovite „Voprosî literaturî”, iniţiată de literatul Jurii Kojevnikov, care publica în nr. 1 al revistei (ianuarie 1962) articolul Să avem o atitudine grijulie faţă de moştenirea clasică. Numărul din august al revistei găzduia opt ecouri la articolul lui Iurii Kojevnikov, între care cel semnat de Andrei Lupan. Scriitorul moldovean se arăta preocupat de ,indezirabilitatea cu care erau tratate operele marilor clasici, sublinia că vederile înapoiate sau chiar declaraţiile 
reacţionare ale unor clasici nu se identifică cu marele conţinut şi valoarea inestimabilă a creaţiei lor". A luat apărarea lui Nicolae Romanenco. Pe adresa redacţiei au venit şi alte materiale, rămase nepublicate (semnate de I. Vasilenco, N. Romanenco, Gh. Bogaci, E. Dvoicenko-Markova ş.a.) care, în opinia redacţiei, „reclamau abordarea creatoare a problemelor moştenirii culturale din RSSM, demonstrând o atitudine responsabilă faţă de valorile literare" (Cojocaru, 2013, p. 126-128). În pofida eforturilor depuse de Secţia de ştiinţe sociale a Academiei şi conducerea Uniunii Scriitorilor, care au salutat şi susţinut iniţiativa revistei „Voprosî literaturî”, la nivel oficial, ,,nu s-a împărtăşit punctul de vedere al lui Iurii Kojevnikov”. În felul acesta, la cel mai înalt nivel politic (Prezidiul CC al PCM), ,,se punea punct disputei dintre tabăra proletcultistă (vulgar-sociologizatoare) a lui I. D. Ceban şi compania şi aripa naţională din ştiinţă, literatură şi cultură. Conducerea de partid era decisă să modeleze de o manieră mult mai autoritară construcţia cultural-identitară din RSSM", constată, în baza datelor de arhivă, istoricul Gheorghe Cojocaru (ibidem, p. 134-135).

Scurta perioadă de aparentă deschidere, propice avântului creativ, se încheiase. „Lucram pe un butoi de pulbere”, va mărturisi, peste ani, istoricul literar Pavel Zavulan, pe atunci cercetător ştiinţific la Academie (Zavulan, 2017, p. 267-268). În anii 1961-1962, în revistele din republică nu a apărut nici un articol despre moştenirea literară, cercetările privind creaţia clasicilor fiind practic sistate. Sunt ani în care nu se editează nimic din sau despre Hasdeu.

Abia anul 1966 vine cu o noutate editorială - volumul colectiv Studii şi materiale despre B. P. Hasdeu (redactori Gh. Bogaci şi H. Corbu), incluzând studiile: B. P. Hasdeu - critic literar (N. Romanenco); Dramele istorice ale lui B. P. Hasdeu (H. Corbu); O comedie insuficient valorificată [Trei crai de la Răsărit] (A. Sadovnic); Aspecte din munca lexicografică a lui B. P. Hasdeu (V. Soloviov); B. P. Hasdeu şi M. Eminescu (L. Ciobanu); Izvoarele ucrainene ale operei lui B. P. Hasdeu (A. Romaneţ); Prezenţa lui B. P. Hasdeu în presa rusă din secolul al XIX-lea (I. Osadcenco) şi compartimentul Însemnări bibliografice şi documente, care cuprinde: B. P. Hasdeu şi A. A. Potebnea (E. Dvoicenko-Markova); O dedicaţie lui M. Kogălniceanu; Carnet lexicografic (N. Romanenco); Primul articol al lui B. P. Hasdeu; Prima menţiune critică despre B. P. Hasdeu; Opt scrisori ale lui B. P. Hasdeu către A. Veselovski (Gh. Bogaci). În prefaţa culegerii coordonatorii anunţă că volumul reia comunicările sesiunii ştiinţifice din martie 1963, prilejuite de împlinirea a 125 de ani din ziua naşterii scriitorului, menţionând că moştenirea literară şi ştiinţifică a lui Hasdeu rămâne încă o problemă insuficient cercetată.

Un an mai târziu (1967), în colecţia Clasicii literaturii moldoveneşti, apar Opere alese, de B. P.-Hasdeu, în două volume. Alcătuire, studiu introductiv, note, comentarii, indice de N. Romanenco. Prezentare grafică: I. Bogdesco.

În 1974, în aceeaşi colecţie, vede lumina tiparului volumul Bogdan Petriceicu Hasdeu. Principii de lingvistică. Studii, recenzii, însemnări. Prefaţă (de fapt, 


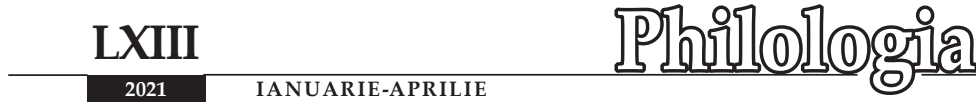

un amplu studiu introductiv): Silviu Berejan. Alcătuire: Nicolae Romanenco. Îngrijirea textului: Pavel Balmuş. Peste ani, reputatul lingvist Silviu Berejan va găsi necesar să menţioneze: „Îi sunt extrem de recunoscător lui Nicolae Romanenco pentru că mi-a oferit posibilitatea, prin prefaţarea volumului în discuţie, să depistez în opera hasdeiană lucruri şi idei care preocupă şi astăzi mintea lingviştilor teoreticieni. B. P. Hasdeu intenţiona să realizeze o operă capitală de lingvistică teoretică. Din păcate, a rămas neterminată. Dar şi numai după fragmentele de care dispunem, desprindem cu surprindere idei excepţional de avansate pentru teoria lingvistică din acea perioadă, printre care câteva dicotomii aproape saussuriene. ...Gânduri deosebit de interesante şi de valoroase expune Hasdeu în privinţa noţiunii şi termenului limbă naţională. El consideră că nu există limbă naţională ca ceva deosebit de toate dialectele în care vorbeşte un popor, adică ca sistem autonom. După părerea lui, limba naţională se prezintă ca un congres al tuturor dialectelor sub preşedinţa unuia din ele. Fiind limba tipică a naţiunii întregi, dialectul dominant devine modul de eleganţă, tintă de imitaţiune pentru toate celelalte dialecte. În felul acesta apare limba literară, vorbită şi scrisă... B. P. Hasdeu merge însă şi mai departe cu anticipările: el consideră că orientarea arheologică (adică spre studierea limbilor antice, a istoriei limbilor) a lingvisticii trebuie înlocuită printr-o nouă orientare (care presupune studiul limbilor moderne în sincronie şi diacronie), numită de el integrală, adică exact aşa cum îşi numeşte noua orientare al doilea mare conaţional al nostru Eugen Coşeriu şi anume: lingvistica integrală. Este foarte semnificativă această coincidenţă de orientări” (Berejan, 2006, p. 102-103).

Creaţia lui Bogdan Petriceicu Hasdeu şi folclorul, substanţialul studiu, în care Mihai Cimpoi vede o intoarcere la izvoare, la rădăcini, o intoarcere la valori (Cimpoi, 2017, p. 7), apare în 1983, la editura Ştiinţa. Este o carte minuţios elaborată, un comentariu inspirat a ceea ce a însemnat pentru mai tânărul Hasdeu, dar şi pentru scriitorul şi savantul în deplină maturitate, eterna, nesecata fântână a creaţiei populare (Ca o paranteză aş remarca faptul că Pavel Zavulan, autorul, şi-a făcut ucenicia la liceul „B. P. Hasdeu” din Chişinău, avându-1 coleg, între alţii, pe Silviu Berejan. Iată că Hasdeu îi apropia din nou, de astă dată pe post de colegi de institut, colegi întru cercetare). Istoricul literar tratează în detaliu opiniile lui B. P. Hasdeu despre folclor; abordează pe larg elementele de folclor în scrierile literare în limba rusă ale scriitorului, precum şi elementele de folclor în poezia acestuia; capitole aparte sunt dedicate aspectelor privind proza şi folclorul, sau celor privind elementele de folclor în scrierile dramatice. O cercetare doctă, cu note bibliografice ce au căutat să cuprindă tot ce se scrisese în materie de Hasdeu şi folclorul la acea dată (evitându-se, pe cât a fost posibil, într-o epocă a drasticei cenzuri, obligatoriile citate de circumstanţă; eram încă în 1983!).

$\mathrm{Cu}$ siguranţ̧ă, cunoaştem, cei mai mulţi dintre literaţi, conţinutul acestei lucrări, dar o să acceptaţi să reiau un mic fragment din capitolul Două poveşti. Lilia, fata de împărat, ,înaintând mereu în genunchi, împletind cununi de flori 
luminoase şi mirositoare, cu lacrimi pe faţă şi cu cântecul pe buze; şi cânta ca apele, când trecea pe lângă râuri, cânta ca frunzele, când străbătea o pădure, cânta ca ciocârlia la răsăritul soarelui şi ca privighetoarea după soare-apune”. E, fără îndoială, continuă istoricul literar, ,una dintre cele mai frumoase imagini (dacă nu chiar cea mai frumoasă) create de Hasdeu în opera sa... Povestea Crinului - fără versurile de la urmă, nelegate nemijlocit de temă, merită să figureze în cele mai alese antologii. La titlurile pe care le are, lui Hasdeu i se poate adăuga încă unul - acela de creator de poveşti" (Zavulan, 2017, p. 162). Interesul scriitorului pentru folclor, conchide cercetătorul, se împleteşte cu preocupările omului de ştiinţă pentru creaţia orală a poporului, pentru limba, istoria şi cultura lui. „Cunoscând tot mai profund tezaurul spiritual al poporului său şi al altor popoare, Hasdeu se convinge de însemnătatea folclorului nu numai pentru destinele literaturii naţionale, ci şi pentru ştiinţele umanitare. Hasdeu a continuat la un nivel mai înalt tradiţiile familiei şi ale scriitorilor patruzecioptişti în ceea ce priveşte atitudinea faţă de folclor" (ibidem, p. 166).

Creaţia lui Bogdan Petriceicu Hasdeu şi folclorul rămâne o lucrare de referinţă. Am considerat necesară, motivată reeditarea acestui studiu (cu litere latine!), lucru care s-a şi întâmplat în 2017.

Scrieri alese, în două volume, 1988 (îngrijire: Nicolae Romanenco şi Lazăr Ciobanu), marcau 150 de ani de la naşterea lui B. P.-Hasdeu - cel care ,rămâne prezent şi profund angajat în contemporaneitate prin spiritul său activ, polemic, scrutător şi ingenios", desprindem din studiul introductiv Bogdan Petriceicu Hasdeu - scriitor şi savant enciclopedist, semnat de N. Romanenco. O ediţie substanţial îmbogăţită, prin spaţiul mai larg acordat creaţiei poetice, cu o ,versiune definitivă" a romanului istoric şi alte lucrări care întregesc profilul lui Hasdeu istoricul şi publicistul, inclusiv pagini din corespondenţa sa cu membrii familiei sau cu personalităţi din ţară şi de peste hotare.

Nicolae Romanenco avea în lucru şi un volum cu texte din Etimologicum Magnum Romaniae, care apare la editura Hyperion, în 1990, cu titlul Vraja cuvintelor. Extrase din Marele dicţionar enciclopedic al limbei istorice şi poporane (este printre primele cărţi editate cu litere latine!). În Postfaţa volumului, antologatorul menţiona: „Pornind de la intenţia lui Hasdeu de a sădi până-n baierele inimii cultul raţional al graiului părintesc, am încercat pentru prima dată în nr. 1 al revistei «Moldova» pe anul 1988 să ofer cititorilor noştri extrase din Marele dicţionar enciclopedic... Publicaţia din revista «Moldova» a fost primită de cititorii ei cu mare interes. De aici a pornit ideea de a compune şi a edita un volum întreg cu asemenea extrase" (Hasdeu, 1990, p. 218-219). În 1991, la aceeaşi editură, este tipărită, în ediţie aparte, poezia-simbol Bradul, în prezentarea grafică a lui Ion Severin.

Prin aceste apariţii se încheie practic o etapă în editarea operei hasdeiene la Chişinău. În doar câţiva ani (anii renaşterii naţionale şi revenirii la alfabetul latin) 




va prinde contur un nou şi amplu proiect editorial: Hasdeu, în Colecţia Moştenire, la editura Ştiinţa (Hasdeu, Scrieri, 1993).

La 10 mai 1990 Nicolae Romanenco îi scria lui Gheorghe Bogaci:

„Dragă Gheorghe [al] lui Teodosie!

Acum lucrez la o monografie despre anii de tinereţe ai lui B. P. Hasdeu..." (In memoriam N. N. Romanenco..., 2006, p. 159).

Proiect neîncheiat, din păcate.

Plin de idei şi de molipsitoare energie (de anii tăi era parcă şi el, spune Victor Cirimpei), prin tot ce a scris, a promovat şi a gândit despre fenomenul Hasdeu, Nicolae Romanenco a menţinut viu interesul, inclusiv prin acel vestit „Cabinet Hasdeu” moscovit, spre care se îndreptau paşii celor pasionaţi cu adevărat. „Nu doar eu am fost dirijat de anumite idei ale lui Nicolae Romanenco - reţinem din amintitul deja eseu al lui Vladimir Beşleagă - ci şi alţi colegi de-ai mei. Printre ei aş putea să numesc pe acei care au devenit ulterior adevăraţi exegeţi ai activităţii şi operei lui Hasdeu: Pavel Balmuş şi Vasile Malaneţchi” (Beşleagă, 2005, p. 115).

Îmi amintesc cu deosebire un moment. Era prin anii '80, atunci când, intenţionând să se documenteze cât mai deplin pentru monografia despre Hasdeu ce o avea probabil în lucru şi profitând de oportunitatea unei deplasări la Chişinău, istoricul literar Ion Oprişan a căutat să se întâlnească şi să discute în mod special cu cercetătorii de la Institut, preocupaţi şi ei de aceleaşi aspecte, în particular cu Vasile Ciocanu, Pavel Zavulan, Lazăr Ciobanu sau Ala Zavadschi-Cojocaru, care tocmai redacta teza de doctorat despre proza lui Hasdeu, din care a şi publicat ulterior câteva fragmente. Ei bine, ştiam de atunci încă de legăturile foarte colegiale dintre eruditul hasdeolog bucureştean şi egalii săi în domeniu P. Balmuş şi V. Malaneţchi, ale căror contribuții n-au întârziat să fie reflectate în compartimentul bibliografic al anunţatei monografii (Oprişan, 1990, p. 606, 617).

Pavel Balmuş, al cărui demers ştiinţific este unul vast şi nuanţat (de la Nicolaus Olahus, Petru Movilă - la Stere, Iorga, Mateevici), a avut o pasiune, veche, constantă şi adevărată: dinastia de cărturari Hâjdău-Hasdeu (sintagma îi aparţine). În tot ce a scris sau conferenţiat a fost atins de partea de zbor intelectual a Hasdeilor. A îngrijit şi întocmit mai multe cărţi, cunoscute. În linia celor discutate aici, vom aminti doar câteva: împreună cu Vasile Ciocanu, scoate, în 1984, un volum colectiv de Studii şi materiale despre Alexandru şi Boleslav Hâjdău, cu un cuvânt-înainte de Haralambie Corbu. În 1998, la editura Arc apare: Bogdan Petriceicu Hasdeu. Publicistică din ziarul „Traian”. 1869-1870. Selecţie: Gabriel Mumjiev. Îngrijirea textului, notă asupra ediţiei, postfaţă: Pavel Balmuş. Volumul reia o parte a imensei opere publicistice (1869-1870), reînviind pagini din istoria, cultura, lumea românească a acelei vremi în toată complexitatea sa - un cert punct de pornire pentru o ediţie completă a publicisticii hasdeiene. 
Întemeiază Centrul Naţional de Hasdeologie (era în februarie 1998, când „Cabinetul Hasdeu” moscovit îmbracă altă haină - chişinăuiană; or, la baza centrului stă donaţia de carte şi documente pe care Nicolae Romanenco a ţinut să le transmită Chişinăului, oraşul care i-a fost drag, aproape de suflet, a cărui nostalgie a purtat-o ani îndelungi şi unde a visat mereu să revină: „mi-ar plăcea să am o căsuţă proprie la Chişinău, unde să pot trăi împreună cu soţia mea Anastasia Starostina, care se ocupă cu literatura română" (In memoriam N. N. Romanenco..., 2006, p. 100), îi mărturisea lui Vasile Malaneţchi într-o scrisoare din 10 aprilie, 1996; şi tot în aprilie al aceluiaşi an pleca spre Clara şi Pavel Balmuş răvaşul în care doamna A. Starostina sublinia: „Sufletul nostru e mângâiat de gândul că există camera memorială «Pro Fide et Patria» şi cabinetul de lucru - «biblioteca». Nicolai Nicolaevici este foarte fericit că a avut norocul de a face ceva folositor pentru cultura Basarabiei lui îndrăgite") (ibidem, p. 190). Sporindu-i rafturile şi căutând să-1 înzestreze cu tot ce era atingător de spiritul hasdeian, Pavel Balmuş impulsionează şi activitatea de cercetare, organizând, neobosit, conferinţe (memorabilul ciclu de conferinţe-comunicări „Pro Academia Hasdeu”), lansări de carte, mese rotunde şi alte manifestări ştiinţifico-culturale. A rezultat un volum consistent: Pro Fide et Patria. Contribuţii la studierea vieţii şi activităţii membrilor familiei Hâjdău-Hasdeu. Fascicula I. Chişinău: Epigraf, 2002. Un volum important, credem, inclusiv prin materialul documentar ce îl înglobează compartimentul al III-lea, privind genealogia neamului Petriceicu-Hâjdău. Reţinem din cuprins un text semnat de Nicolae Romanenco, elaborat în 1992 (Alexandru Hâjdău în „Dosarul nr. 90"), şi alte două (Contribuţii documentare cu privire la studiile de gimnaziu ale lui B. P. Hasdeu; Chipul lui Bogdan Petriceicu Hasdeu în arta plastică. Bustul în bronz, realizat în 1936, de sculptorul Alexandru Plămădeală), aparţinând lui Vasile Malaneţchi, şi el un împătimit al cercetării, punând un preţ deosebit pe documentul de arhivă.

Parcursul acestor lungi decenii, când mai propice cercetării/ editării, când mai puţin favorabil, în virtutea multor circumstanţe, numără titluri de articole (Lidia Kulikovski ne anunţă un total de 270, dintre care 36 în limba rusă, inserate în periodicele din republică până în 2007), mai mari, mai mici; uneori magistrale, alteori simple consemnări, în „Nistru”, „Viaţa Basarabiei”, „Literatură şi artă”, „Orizontul”, „Revistă de lingvistică şi ştiinţă literară” (a cărei copertă, în colontitlu, era înnobilată de chipul gânditorului şi de sugestivul citat: Orice cuvânt oglindeşte un lucru, o fiinţă, o idee, o datină..., evident, la stăruinţa lui Silviu Berejan, redactorul-şef al revistei), „Destin românesc”; dar şi în cărţi de autor. De exemplu, pe Hasdeu, romanticul social, Hasdeu gânditorul, îl regăsim în Duminica valorilor (1989), în volumul-medalion Sfinte firi vizionare (1995), în Istoria deschisă a literaturii române din Basarabia (1996) ale lui Mihai Cimpoi; dar şi în volumul Reîntoarcerea valorilor de Ion Vasilenco, editat 


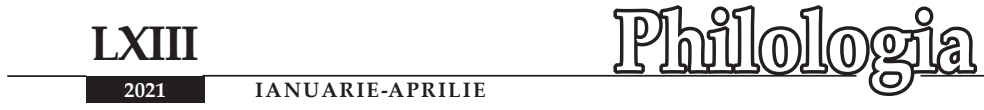

de Institutul de Filologie, în 2008, cu efortul lui Lazăr Ciobanu şi o prefaţă de Mihai Cimpoi (volum care reia, între altele, şi articolele: B. P. Hasdeu-scriitor, gânditor, luptător, publicat în „Cultura Moldovei”, 1957; Opera literară a lui B. P. Hasdeu, „Moldova socialistă”, 1958; Poezia lui B. P. Hasdeu, preluat din Studii de literatură şi folclor, 1963, fatidicul an, pentru istoricul literar Ion Vasilenco, când începe, la propriu, calvarul lui pământesc, care va duce la tragicu-i sfârşit, în primăvara lui 1977).

Multe titluri şi aproape tot atâtea nume, la cele amintite deja adăugându-se: Vasile Badiu; Efim Levit; Vlad Chiriac; Ion Bejenaru; Vasile Bahnaru; Gheorghe Bobână (care, de curând, ne dă un bun capitol Filosofi ai istoriei. B. P. Hasdeu (1838-1907), în Istoria filosofiei româneşti. Curs de prelegeri. Partea a II-a. Chişinău, 2018, p. 214-242); Grigore Bostan; Grigore Botezatu; Victor Cirimpei, care s-a bucurat şi el de girul lui N. Romanenco, primind de la acesta materiale atingătoare de preocupările etno-folclorice româneşti ale liceanului Tadeu [Bogdan Petriceicu-Hasdeu], precum şi studiul cu descifrări Reminiscenţe ale credinţelor dacice; a publicat articole privind Creaţia populară şi B. P. Hasdeu sau Doina din perspectiva lui Hasdeu; Anton Comerzan, Gheorghe Gonţa, Alexandrina Matcovschi, Eliza Botezatu; Ion Şpac; Ion Dron; Dumitru Coval, care punctează Probleme de critică, istorie şi teorie literară în publicistica lui B. P. Hasdeu; Vasile Pavel; Vasile Nastasiu; Lilia Cozma-Hanganu, cu un studiu B. P. Hasdeu şi bulgarii; Svetlana Coandă; Vitalie Belâi; Ion Ciocanu; Ion Varta; Sergiu Pavlicencu, cu Preocupări de hispanistică la B. P. Hasdeu; Vitalie Răileanu; Călina Trifan; Ioan Mânăscurtă, Nicolae Dabija; Andrei Vartic; Nina Negru, cu titluri incitante şi abordări care se reţin, „Basarabii” şi „Basarabia” în interpretarea lui B. P. Hasdeu sau „Chestiunea israelită” $\hat{n}$ publicistica lui B. P. Hasdeu şi Eminescu; Lidia Kulikovski care semnează studiul introductiv - Hasdeu în timpul şi spaţiul Republicii Moldova - la un foarte util catalog bibliografic (de care ne-am ghidat şi noi în comunicarea de faţă), întocmit de Pavel Balmuş dimpreună cu Clara Balmuş, Moştenirea literar-spirituală a dinastiei de cărturari Hâjdău-Hasdeu în bibliotecile chişinăuene (2007), care înregistrează tot ce s-a editat din opera lui B. P.-Hasdeu şi despre B. P.-Hasdeu în Basarabia, inclusiv cărţi apărute în alte ţări (România, Rusia, Ucraina, Franţa), care se regăsesc în bibliotecile din Chişinău.

„Visez la o ediţie integrală Alexandru Hâjdău”, mărturisea Pavel Balmuş într-un interviu acordat lui Vasile Malaneţchi, cu prilejul apariţiei volumului Aleksandr Hijdeu. Izbrannoe, întocmită de N. N. Romanenco şi P. T. Balmuş (schiţă biografică şi comentarii), 1986 („Literatură şi artă”, 1987, 12 nov.). A mers spre acest vis, editând Alexandru Hâjdău. Clipe de inspiraţie, la Litera Internaţional, 2004. Zece ani mai târziu, în 2014, la editura Vicovia 
din Bacău, scoate volumul Alexandru şi Boleslav Hâjdău. Scrieri. Poezie. Proză. Publicistică. Genealogii. Traduceri din limba rusă a vremii: C. Stamati, B. P.-Hasdeu, Z. C. Rally-Arbore, N. Dabija, Cl. Balmuş, P. Balmuş, care asigură şi selecţia, prefaţa, tabelul cronologic, notele şi comentariile; volum pe care a reuşit să-1 lanseze, în luna decembrie a aceluiaşi an, la Iaşi. Şi în această carte, a ţinut să vină cu precizarea privind data naşterii scriitorului B. P.-Hasdeu, aspect asupra căruia, pornind de la date-document, a stăruit în mai multe rânduri.

La pagina 15 a acestui volum citim:

\section{, $\mathbf{1 8 3 8}$}

februarie

«...La douăzeci şi şase [mai corect: 28 , „stil nou”, pe cel „vechi” fiind abia 16] februarie, în familia moşierului din satul Cristineşti, efor de onoare al şcolilor din ţinutul Hotin, domnul Alexandru, fiul lui Thadeu Hâjdău, de credinţă ortodoxă, şi al soţiei legitime a acestuia Elizaveta, fiică a lui Theophil, de aceeaşi religie, s-a născut feciorul Thadeu... [ulterior: Bogdan Petriceicu Hasdeu]»".

Parcursul biografic al lui B. P. Hasdeu, vasta sa operă literară şi ştiinţifică au constituit obiectul de studiu atent şi documentat al unei generoase cohorte de oameni de litere basarabeni, ale căror abordări fac dovada unicităţii spiritului hasdeian şi a profundei sale angajări în contemporaneitate. Aceste câteva punctări s-au vrut o pledoarie pentru toţi cei care, prin mult-puţinul care le-a fost îngăduit, au contribuit ieri/ contribuie astăzi la cunoaşterea-citirea cărţii mereu deschise Hasdeu.

\section{Referințe bibliografice:}

BEREJAN, Silviu. Sumare, dar profund omenești aduceri-aminte. În: In memoriam N. N. Romanenco. Cum să trăieşti în vremurile normale. Amintiri. Corespondenţă. Evocări. Москва: Критерион, 2006, p. 101-103.

BEŞLEAGĂ, Vladimir. Modelul Nik. Nik. În: Sud-Est cultural, 2005, nr. 4, p. 106118. Reluat în: In memoriam N. N. Romanenco. Cum să trăieşti în vremurile normale. Amintiri. Corespondenţă. Evocări. Москва: Критерион, 2006, p. 5-25.

CIMPOI, Mihai. Obsesia şi nostalgia ,fântânelor”. [Cuvât-înainte] la: Pavel Zavulan. Pagini de istorie literară. Chişinău: Farmec Lux, 2017, p. 7-8.

COJOCARU, Gheorghe. Impactul Congresului al XXII-lea al PCUS asupra ştiinţei lingvistice şi literaturii din RSS Moldovenească. În: Akademos, 2013, nr. 4 (31), p. 125135. Vezi în acest sens şi articolul lui H. Corbu. O filă din istoria bătăliei pentru literatura clasică, în volumul Dincolo de mituri şi legende. Studii, eseuri, articole, Chişinău: Cartea Moldovei, 2004, p. 339-352.

HASDEU, Bogdan Petriceicu. Vraja cuvintelor. Extrase din Marele dicţionar enciclopedic al limbei istorice şi poporane. Postfaţă de Nicolae Romanenco. Chişinău: Hyperion, 1990. 
HASDEU, Bogdan Petriceicu. Scrieri. Volumul I. Poezii. Text îngrijit, studiu introductiv, note şi comentarii de Stancu Ilin. Tabel cronologic de I. Oprişan. Chişinău: Ştiinţa, 1993. Este primul volum (din seria de 16 volume anunţată iniţial). Au urmat alte 18 volume. Ediţia/ editarea continuă.

In memoriam N. N. Romanenco. Cum să trăieşti în vremurile normale. Amintiri. Corespondenţă. Evocări [Alcătuire: A. Starostina]. Москва: Критерион, 2006, 262 p.

KULIKOVSKI, Lidia. Hasdeu în timpul şi spaţiul Republicii Moldova. [Cuvântînainte la]: Moştenirea literar-spirituală a dinastiei de cărturari Hâjdău-Hasdeu în bibliotecile chişinăuene. Chişinău, 2007, p. 10-30.

Moştenirea literar-spirituală a dinastiei de cărturari Hâjdău-Hasdeu în bibliotecile chişinăuene. Catalog-bibliografie. Ediţie îngrijită de conf. univ. dr. Lidia Kulikovski. Alcătuitori: Clara Balmuş, Pavel Balmuş. Chişinău: Elan Poligraf, 2007, 189 p.

OPRIŞAN, I. Romanul vieţii lui Bogdan Petriceicu Hasdeu. Bucureşti: Minerva, 1990. Vezi şi ediţia a II-a, B. P. Hasdeu sau setea de absolut. Tumultul şi misterul vieţii. Bucureşti: Vestala, 2001, p. 553, 564.

ZAVUlAN, Pavel. Pagini de istorie literară. Alcătuire: Svetlana Korolevski, Vlad Caraman, Ala Zavadschi-Cojocaru. Cuvânt-înainte: Mihai Cimpoi. Chişinău: Farmec Lux, 2017, 270 p.

Notă: Articolul a fost realizat în cadrul proiectului de cercetare 20.80009.1606.03 Contexte socioculturale autohtone şi interconexiuni europene în creaţia populară şi literatura cultă din Basarabia (sec. XIX până în prezent), Institutul de Filologie Română „B. P.-Hasdeu” al MECC. 